\title{
Formation and structural transformations of nanoparticles in the $\mathrm{TiO}_{2}-\mathrm{H}_{2} \mathrm{O}$ system
}

\author{
O. V. Almjasheva \\ Saint Petersburg Electrotechnical University "LETI", \\ ul. Professora Popova 5, 197376 St. Petersburg, Russia \\ almjasheva@mail.ru
}

PACS 64.60.A-; 64.70.Nd

DOI 10.17586/2220-8054-2016-7-6-1031-1049

Results thermodynamic analysis of processes in the $\mathrm{TiO}_{2}-\mathrm{H}_{2} \mathrm{O}$ system in a wide range of variation of parameters determine the regions of sustainable existence of titanium dioxide in the form of rutile and anatase modification. The results of thermodynamic prediction on the possibility and conditions of sustainable existence of $\mathrm{TiO}_{2}$ with the rutile structure have been confirmed in experiments.

Keywords: nanoparticles, $\mathrm{TiO}_{2}$, anatase, retile, thermodynamic analyses, structural transformations.

Received: 20 August 2016

Revised: 11 November 2016

\section{Introduction}

Despite the large number of works on formation, technology, structure and properties of compounds of different composition and structure in the $\mathrm{TiO}_{2}-\mathrm{H}_{2} \mathrm{O}$ system (for instance, see [1]), by now, there is no consensus on the stability, composition and structure of a significant number of compounds in this system. Such compounds include hydrated forms of titanium oxide. As mentioned in [2], such uncertainty exists even at the level of names for hydrated forms of $\mathrm{TiO}_{2}$. This is determined by the uncertainty of the composition of hydrated titanium dioxide that depends on the synthesis conditions and changes with time $[2,3]$.

Data on the phase and chemical transformations in the $\mathrm{TiO}_{2}-\mathrm{H}_{2} \mathrm{O}$ system in the $P-T$-coordinates is quite limited by now. In particular, there is a diagram of transformations proposed in [4]. In addition to this work, there are a number of studies on phase transformations in titanium dioxide.

For instance, in [5-12], the structural states of titanium dioxide in a wide range of temperature and pressure changes summarized in [13] were studied. Along with the literature data, it includes the obtained data as $P-T$ constitutional diagram for $\mathrm{TiO}_{2}$. Previous research [13], in addition to the rutile structure, which is equilibrium in a wide range of temperatures, showed the constitutional diagrams include a region for the existence of a high-pressure phase $-\mathrm{TiO}_{2}$-II, which has a structure similar to $\alpha-\mathrm{PbO}_{2}$ [7]. In addition, these $P-T$-diagrams include P-T-regions for the existence of anatase and brookite titanium dioxide structures. However, in [13], it was noted that these phases were used as precursors for further studies of phase transitions in them with increasing temperature and pressure, i.e. reverse transition of rutile or $\mathrm{TiO}_{2}$ with a structure of $\alpha-\mathrm{PbO}_{2}\left(\mathrm{TiO}_{2}\right.$-II $)$ into the anatase or brookite structure was not observed. In further studies, this allowed many authors [1] to conclude that the phases of anatase and brookite were metastable. However, the unusual coincidence of the $P-T$-boundary of transition for anatase to rutile shown by different authors and marked on the $P-T$-constitutional diagram of titanium dioxide in [13] should be noted.

In [4], on the $P-T$-diagram, where the state of the substance was studied under hydrothermal conditions, i.e., actually - the state of $\mathrm{TiO}_{2}$ in the $\mathrm{TiO}_{2}-\mathrm{H}_{2} \mathrm{O}$ system, only the phase transition of anatase titanium dioxide to the rutile modification was observed. The absence of information on chemical transformation $\mathrm{Ti}(\mathrm{OH})_{4} \rightarrow \mathrm{TiO}_{2}+\mathrm{H}_{2} \mathrm{O}$ in the diagram is apparently associated with the ambiguity of the information on the temperature of this transition. For example, in [15], it was stated that, during the thermal treatment of freshly prepared titanium gels without separating the solid phase from the mother liquor, crystallization of the amorphous gel of $\mathrm{TiO}_{2} \cdot \mathrm{nH}_{2} \mathrm{O}$ with the formation of the anatase structure can begin at $60-100{ }^{\circ} \mathrm{C}$. However, in [14], it was shown that the gel based on titanium dioxide is in the amorphous state up to $\sim 200{ }^{\circ} \mathrm{C}$, and the crystallization starts only when the temperature rises to $250-350{ }^{\circ} \mathrm{C}$. The crystallization onset temperature can be decreased by hydrothermal treatment of hydrated titanium dioxide [16].

The $\mathrm{Ti}(\mathrm{OH})_{4}$ composition is often ascribed only to freshly precipitated hydrated titanium dioxide. Freshly precipitated $\mathrm{Ti}(\mathrm{OH})_{4}(\alpha$-form $)$ is subject to aging, which occurs rapidly, even at room temperature. The final product of aging, according to [2], is hydrated titanium dioxide ( $\beta$-form), to which the conditional formula of 
$\mathrm{H}_{2} \mathrm{TiO}_{3}$ is attributed. Heating accelerates its aging. It is supposed that ignition can induce not only dehydration, but also partial reduction of titanium dioxide. The progress of the latter process in air is in doubt due to the stability of titanium in the Ti (IV) oxidation state, which is mentioned in many works $[1,3]$.

Along with a variety of structural modifications of hydrated titanium dioxide, there is morphological diversity of particles - from particles of isometric shape to particles of plate-like and nanotubular shapes, which are characteristic, for example, for $\mathrm{H}_{2} \mathrm{Ti}_{3} \mathrm{O}_{7}$ [17].

Thus, the uncertainty in the dependence of chemical, structural, and morphological transformations in the $\mathrm{TiO}_{2}-$ $\mathrm{H}_{2} \mathrm{O}$ system on external conditions, especially the temperature, resulting from the analysis of the literature data, suggests the need for further study of these processes, including thermodynamic analysis of these transformations.

\section{Thermodynamics of chemical and structural phase transformations in the $\mathrm{TiO}_{2}-\mathrm{H}_{2} \mathrm{O}$ system}

The thermodynamic analysis of the conditions for the stable existence of titanium oxide, in which titanium has an oxidation state of less than 4+, conducted with the use of the Ivtanthermo thermodynamic database [18], depending on the temperature and oxygen partial pressure (Fig. 1), shows that the equilibrium existence of such compounds is thermodynamically possible only in a reducing atmosphere and at a sufficiently high temperatures. According to the results of thermodynamic calculations (Fig. 1), in a reducing atmosphere and at increased temperatures, the following chain of redox processes is observed:

$$
\begin{aligned}
\mathrm{TiO}_{2} \Rightarrow \frac{1}{n} \mathrm{Ti}_{n} \mathrm{O}_{2 n-1}+ & \frac{1}{n} \mathrm{O}_{2} \\
\Rightarrow \frac{1}{2} \mathrm{Ti}_{2} \mathrm{O}_{3}+\frac{1}{2} \mathrm{O}_{2} & \\
& \Rightarrow \mathrm{TiO}+\frac{1}{2} \mathrm{O}_{2} .
\end{aligned}
$$

Reduction to $\mathrm{TiO}$ requires the use of significantly more stringent reducing conditions than reduction to $\mathrm{Ti}_{n} \mathrm{O}_{2 n-1}$ and $\mathrm{Ti}_{2} \mathrm{O}_{3}$, as can be concluded based on the analysis of the calculation results (Fig. 1).

During calculation, the impact of particle size upon the thermodynamics of redox reactions was not taken into account. It seems that these effects can not significantly change the results presented in Fig. 1, at least for particles with a size of tens of nanometers. Thus, for the temperature range below that of the recrystallization processes, i.e. below the melting point of surface (nonautonomous) phase based on $\mathrm{TiO}_{2}-\mathrm{T}_{m 2 n}[19,20]$ ), there is a potential possibility to obtain nanoparticles of titanium oxide in different oxidation states, less than $4+$, by redox reactions.

The thermodynamic analysis of the possibility for forming titanium dioxide of different polymorph modifications during decomposition of hydrated titanium dioxide is of interest. Thermodynamic calculations were carried out with the assumption that hydrated titanium dioxide has a composition of $\operatorname{Ti}(\mathrm{OH})_{4}$ and is in the crystalline or amorphous state.



FIG. 1. $T-\lg p_{\mathrm{O} 2}$ regions of existence of titanium oxide in the "hydrogen-water vapor" atmosphere 
Due to the fact that the thermodynamic data on formation enthalpy, entropy and heat capacity for $\mathrm{Ti}(\mathrm{OH})_{4}$ $\left(\Delta H(T), S(T), c_{p}(T)\right)$ are absent in the literature, this data was obtained with the use of various approximate calculation methods. In particular, the method of comparative calculation proposed by Karapetyants [21] was used, which showed good agreement with the experimental data in the evaluation of the thermodynamic properties of a similar compound $-\mathrm{Zr}(\mathrm{OH})_{4}$ [22]. This method is based on a comparison of the relevant characteristics of two similar rows (I and II). To assess $H_{298}\left(\mathrm{Ti}(\mathrm{OH})_{4}\right), S_{298}\left(\mathrm{Ti}(\mathrm{OH})_{4}\right)$ and $c_{p}\left(\mathrm{Ti}(\mathrm{OH})_{4}\right)$, thermodynamic data for the following compounds were used: $\mathrm{AlX}_{3}, \mathrm{MgX}_{2}, \mathrm{CaX}_{2}, \mathrm{SrX} 2, \mathrm{FeX}_{2}, \mathrm{ZrX}_{4}$, where $\mathrm{X}=\mathrm{F}^{-}, \mathrm{Cl}^{-}, \mathrm{Br}^{-}, \mathrm{OH}^{-}$[23]. The results of the calculations are shown in Table 1.

TABLE 1. Thermodynamic data for $\mathrm{Ti}(\mathrm{OH})_{4}$

\begin{tabular}{|c|c|l|}
\hline Thermodynamic property & Value & Note \\
\hline \multirow{2}{*}{$H_{298}, \mathrm{~kJ} / \mathrm{mol}$} & -1358.98 & calculation according to [21] \\
\cline { 2 - 3 } & -1084 & calculation according to [24] \\
\hline \multirow{2}{*}{$S_{298}, \mathrm{~kJ} / \mathrm{mol} \cdot \mathrm{K}$} & 164.75 & calculation according to [21] \\
\cline { 2 - 3 } & 127.9 & calculation according to [25] \\
\hline \multirow{2}{*}{$c_{p}, \mathrm{~kJ} / \mathrm{mol} \cdot \mathrm{K}$} & 125.52 & calculation according to [21] \\
\cline { 2 - 3 } & 131.1 & calculation according to [25] \\
\hline
\end{tabular}

Due to the fact that the structure of the substance in an amorphous state, at least in the first coordination sphere, is close to the melt structure [26,27], the enthalpy of amorphization of hydrated titanium dioxide was evaluated based on empirical correlation proposed in [27].

$$
\Delta H_{298 \text { amorphization }}=0.3-0.5 \Delta H_{\text {melt }},
$$

where $\Delta H_{298}$ amorphization $^{-}$amorphization enthalpy, $\mathrm{kJ} / \mathrm{mol} ; \Delta H_{\text {melt }}-$ melting enthalpy, $\mathrm{kJ} / \mathrm{mol}$. Thus, the enthalpy of $\mathrm{TiO}_{2} \cdot n \mathrm{H}_{2} \mathrm{O}(n=2)$ in an amorphous state can be taken as:

$$
\Delta H_{298 \text { am }}^{0}=\Delta H_{298 \text { cr }}^{0}+0.4 \Delta H_{\text {melt }}=-1331 \pm 10 \mathrm{~kJ} / \mathrm{mol},
$$

$\Delta H_{\text {melt }}$ is taken as $\Delta H_{\text {melt }}=68 \mathrm{~kJ} / \mathrm{mol}$ (data according to the IVTANTHERMO database [18]).

Based on Gibbs energy calculations for the reaction of dehydration of titanium hydroxide, shown in Fig. 2, it can be concluded that the formation of both anatase and rutile modifications of $\mathrm{TiO}_{2}$ is possible throughout the whole calculated temperature and pressure range. This was the case, regardless of whether crystalline or amorphous $\mathrm{Ti}(\mathrm{OH})_{4}$ was considered as the starting material.



FIG. 2. Dependence of the Gibbs energy of dehydration of $\mathrm{Ti}(\mathrm{OH})_{4 c r}$ on the temperature and pressure for reaction $\mathrm{Ti}(\mathrm{OH})_{4}=\mathrm{TiO}_{2}+2 \mathrm{H}_{2} \mathrm{O}$

The inaccuracy in the determination of the thermodynamic properties of $\operatorname{Ti}(\mathrm{OH})_{4}$, apparently, can not affect the quality of conclusion on the instability of the hydrated form of titanium dioxide, since the $\Delta G$ value of the 
dehydration reaction in absolute value significantly exceeds the possible errors in its calculation in the entire range of considered temperatures and pressures. Thus, the hydrated form of titanium dioxide $\left(\mathrm{Ti}(\mathrm{OH})_{4}\right)$ in the considered range of $P-T$-conditions is unstable and can be transformed into both rutile and anatase forms.

Conclusion on thermodynamic instability of the hydrated form of titanium dioxide is supported by the results of experimental studies [1-3], in which it is shown that under certain conditions, even at temperatures close to room temperature, crystallization of amorphous gel of $\mathrm{TiO}_{2} \cdot n \mathrm{H}_{2} \mathrm{O}$ occurs with the formation of titanium dioxide with the anatase structure. Thus, based on the results of the analysis, it can be concluded that the kinetic factors, instead of thermodynamic factors, are determining in the dehydration process.

In addition to temperature and pressure influencing the possibility of the formation of a crystalline modification of $\mathrm{TiO}_{2}$ in the dehydration of $\mathrm{Ti}(\mathrm{OH})_{4}$, the influence of the size effect should be taken into account. To assess the effect of the size factor, the dependence between the Gibbs energy of the reaction of decomposition of titanium hydroxide and the size of formed particles of $\mathrm{TiO}_{2}$ was calculated. The calculation was carried out based on the known relations (for instance, see [28]).

The surface energy values for rutile and anatase titanium dioxide given in the literature are quite different. Based on the theoretical analysis given in $[29,30]$, the surface energy value of rutile was assumed to be $1.5 \mathrm{~J} / \mathrm{m}^{2}$ and $1.42 \mathrm{~J} / \mathrm{m}^{2}$, respectively. Whereas, based on the results of experimental measurement of the excess enthalpy of grain boundaries [31], the value of surface energy for the rutile modification of titanium dioxide ranges from 1.3 to $1.7 \mathrm{~J} / \mathrm{m}^{2}$. In $[32,33]$, the rutile surface energy was taken as $1.5 \mathrm{~J} / \mathrm{m}^{2}$, which is the average of these values, and the anatase surface energy was taken as 0.85 of the rutile surface energy, i.e. 1.275 , that was associated with a corresponding increase in the molar volume of anatase compared to rutile. A more thorough analysis carried out in [34] allowed determination of the temperature dependence of the surface energy for both rutile and anatase as:

$$
\begin{gathered}
\sigma_{\text {rutil }}=1.91-1.48 \cdot 10^{-4}(T-298), \\
\sigma_{\text {anatase }}=1.32-1.48 \cdot 10^{-4}(T-298),
\end{gathered}
$$

where $\sigma_{\text {rutil }}, \sigma_{\text {anatase }}$ - surface energy of anatase and rutile, respectively, $\mathrm{J} / \mathrm{m}^{2} ; T$ - temperature, K. It should be noted that the value of the surface energy of rutile, determined according to [34], is much higher than the values given in [29-32], while $\sigma_{\text {anatase }}$ remains almost unchanged (Table 2). This may be due to higher difficulty of determining the influence of the relaxation processes on the surface energy of rutile having a higher density than titanium dioxide anatase.

In further thermodynamic calculations, the data given in [34] are used, which are more founded and can be presented as:

$$
\begin{gathered}
\sigma_{\text {rutil }}=1.9541-1.48 \cdot 10^{-4} T, \\
\sigma_{\text {anatase }}=1.364-1.48 \cdot 10^{-4} T,
\end{gathered}
$$

where the first term describes mainly the enthalpy component of the surface free energy, and the coefficient in front of temperature describes mainly the entropy component.

The dependence between the size of critical nuclei of anatase and rutile formed during dehydration of $\operatorname{Ti}(\mathrm{OH})_{4}$ and different values of temperature and pressure in the $\mathrm{TiO}_{2}-\mathrm{H}_{2} \mathrm{O}$ system was calculated (Figs. 3, 4).
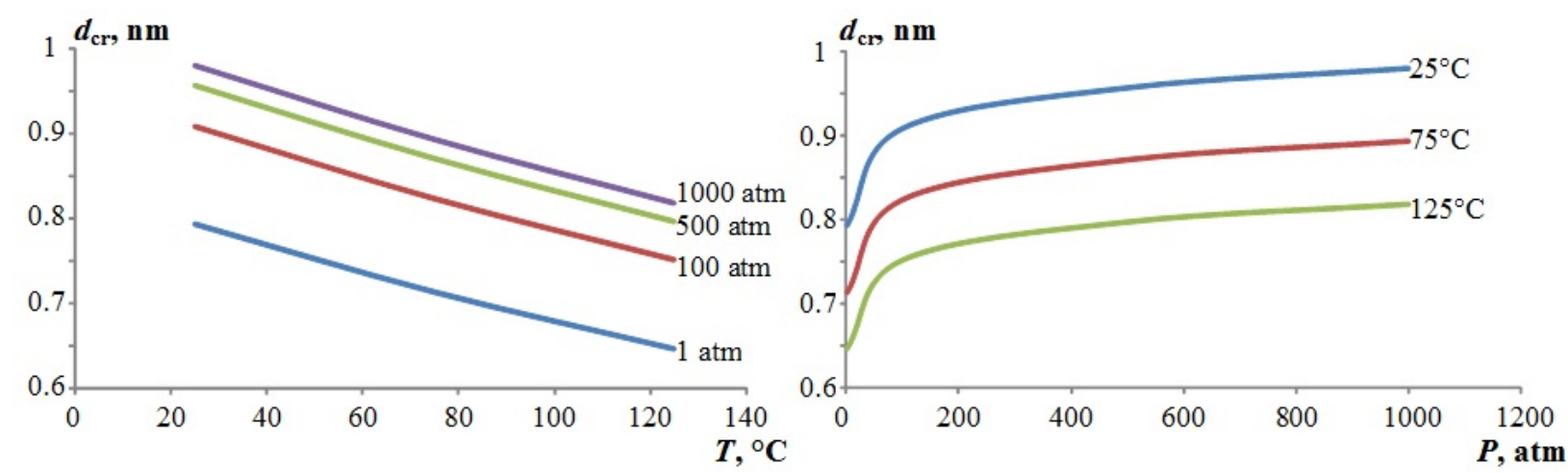

FIG. 3. Dependence of the size of the critical nucleus of $\mathrm{TiO}_{2}$ (rutile) on the pressure and temperature during dehydration of $\mathrm{Ti}(\mathrm{OH})_{4}$

The obtained values for the critical nucleus sizes in the temperature range of nanocrystal formation according to the analysis of the calculation results shown in Fig. 3 and 4 range from 0.5 to $1 \mathrm{~nm}$. Additionally, the lowest values 
TABLE 2. Values of the surface energy of rutile $\left(\sigma_{\text {rutil }}\right)$ and anatase $\left(\sigma_{\text {anatase }}\right)$ modifications of titanium dioxide

\begin{tabular}{|c|c|c|}
\hline \multicolumn{2}{|c|}{ Value, $\mathrm{J} / \mathrm{m}^{2}$} & \multirow{2}{*}{ References } \\
\hline$\sigma_{\text {rutil }}$ & $\sigma_{\text {anatase }}$ & \\
\hline 1.5 & - & [29] \\
\hline 1.42 & - & {$[30]$} \\
\hline $1.3-1.7$ & - & {$[31]$} \\
\hline 1.5 & 1.275 & {$[32]$} \\
\hline 1.5 & 0.85 & {$[32]$} \\
\hline $1.91-1.865$ & $1.32-1.275$ & {$[34]$} \\
\hline "clean surface" & "clean surface" & \\
\hline$(100)-0.60$ & $(001)-0.51$ & \\
\hline$(011)-0.95$ & $(100)-0.39$ & \\
\hline$(110)-0.47$ & $(101)-0.35$ & "clean surface" - [35] \\
\hline "hydrated surface" & "hydrated surface" & "hydrated surface" - [33] \\
\hline$(100)-1.57$ & $(001)-1.55$ & \\
\hline$(011)-1.79$ & $(100)-1.13$ & \\
\hline$(110)-1.08$ & $(101)-1.03$ & \\
\hline $0.47-0.95$ & $0.35-0.81$ & {$[36]$} \\
\hline $0.31-1.65$ & $0.44-1.09$ & {$[36]$} \\
\hline
\end{tabular}
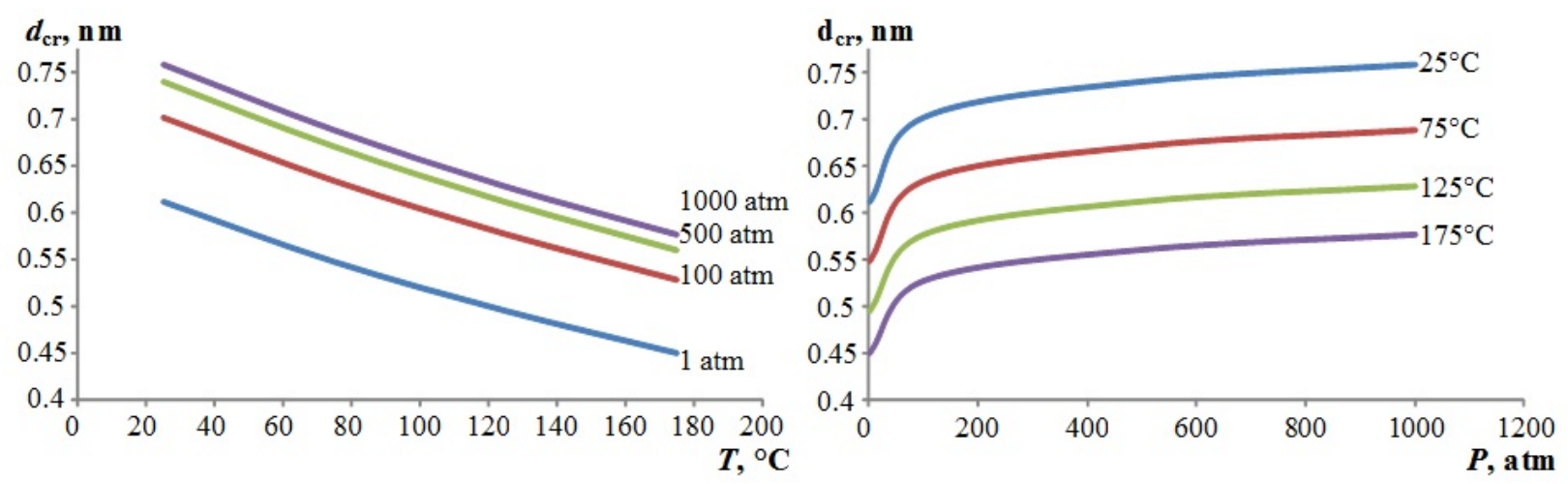

FIG. 4. Dependence of the size of the critical nucleus of $\mathrm{TiO}_{2}$ (anatase) on the pressure and temperature during dehydration of $\mathrm{Ti}(\mathrm{OH})_{4}$

for critical nuclei are observed at minimum values of pressure and maximum values of dehydration temperature for $\mathrm{Ti}(\mathrm{OH})_{4}$. It should be noted that the calculated values of the critical nucleus size are beyond the applicability of the approach used. In particular, for surfaces with such curvature, it is necessary to take into account the dependence between the surface energy and the radius of curvature [37-39], and the term of crystalline titanium dioxide particle at such values of $d$ does not make sense.

Comparison of sizes for the critical nuclei of anatase and rutile shows that the size of the critical nucleus for the $\mathrm{TiO}_{2}$ anatase modification is somewhat less than that of rutile one. In addition, it should be noted that the very small values for the size of the critical nucleus of rutile and anatase show an extremely weak trend in the formation of anatase nuclei compared to the formation of rutile nuclei, and the possibility of forming $\mathrm{TiO}_{2}$ of any of these modifications already at room temperature during the dehydration of $\operatorname{Ti}(\mathrm{OH})_{4}$. 
Thermodynamic analysis of the phase transition:

$$
\mathrm{TiO}_{2} \text { (anatase) } \rightarrow \mathrm{TiO}_{2} \text { (rutil) }
$$

showed that in different variants of thermodynamic data used (IVTANTHERMO database [18], JANAF reference book [40], data given in Table 3) the bulk phase with the rutile structure is thermodynamically stable throughout solid phase titanium dioxide's range of existence (Fig. 5).

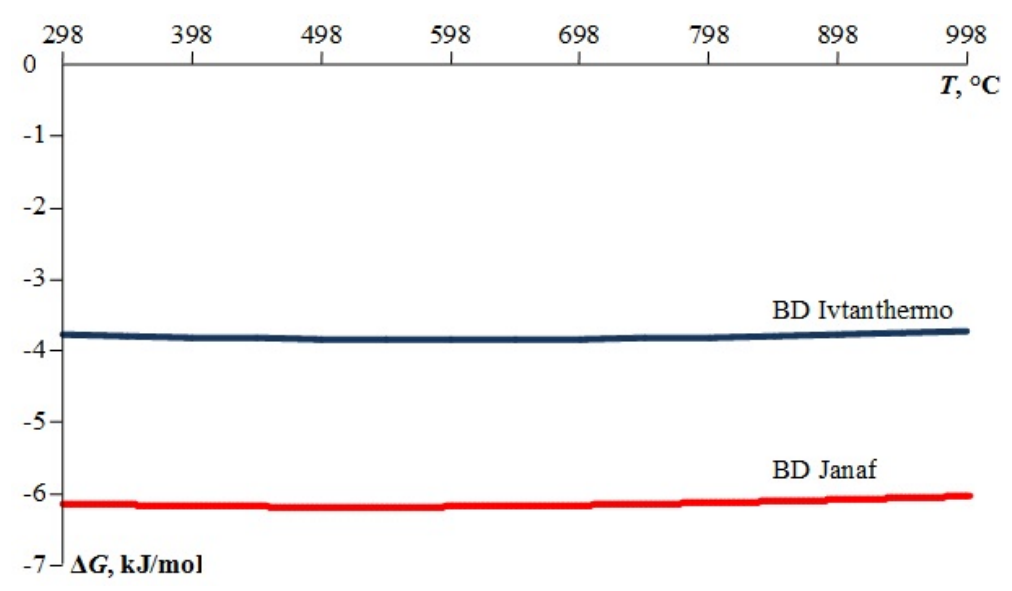

FIG. 5. Dependence of a change in the molar Gibbs energy in transition (3) on the temperature: 1) calculation based on the IVTANTHERMO data [18]; 2) calculation based on the JANAF data [40]

However, since the surface energy of anatase is lower than the surface energy of rutile (Table 2), based on the analysis of ratio:

$$
\Delta G_{\text {anatase } \rightarrow \text { rutil }}^{m}=\Delta G_{b . p .(\text { anatase } \rightarrow \text { rutil })}^{m}(T ; P)+\left(\sigma_{\text {rutil }} \cdot S_{\text {rutil }}+\sigma_{\text {anatase }} \cdot S_{\text {anatase }}\right),
$$

where, $\Delta G_{\text {anatase } \rightarrow \text { rutil }}^{m}$ - change in molar Gibbs energy during transition of particles from anatase to rutile structure; $\Delta G_{b . p \text {. (anatase } \rightarrow \text { rutil })}^{m}$ - change in molar Gibbs energy of bulk phases of $\mathrm{TiO}_{2}$ during transition of titanium dioxide from anatase to rutile structure; $\sigma_{\text {rutil (anatase) }}$ - specific surface energy of rutile (anatase); $S_{\text {rutil(anatase) }}$ - surface of one mole of titanium dioxide with the rutile (anatase) structure. It can be expected that in the presence of a certain amount of particles of anatase, this phase will be more thermodynamically stable than the phase with the rutile structure.

Assuming that the particles have a shape close to spherical, expression (4) can be presented as:

$$
\Delta G_{\text {anatase } \rightarrow \text { rutil }}^{m}=\Delta G_{b . p .(\text { anatase } \rightarrow \text { rutil })}^{m}+6\left(\frac{\sigma_{\text {rutil }} \cdot V_{\text {rutil }}^{m}}{d_{\text {rutil }}}+\frac{\sigma_{\text {anatase }} \cdot V_{\text {anatase }}^{m}}{d_{\text {anatase }}}\right),
$$

where $V_{\text {rutil(anatase) }}^{m}$ - molar volume of $\mathrm{TiO}_{2}$ with a rutile (anatase) structure; $d_{\text {rutil(anatase) }}$ - diameter of the rutile (anatase) particles.

For the case when one anatase particle is transformed into one rutile particle, expression (2) can be presented as:

$$
\begin{aligned}
& \Delta G_{\text {anatase } \rightarrow \text { rutil }}^{m}\left(T, P, d_{\text {anatase }}\right)=\Delta G_{b . p .(\text { anatase } \rightarrow \text { rutil })}^{m}(T, P)+ \\
& 6 \frac{\sigma_{\text {anatase }} \cdot V_{\text {anatase }}^{m}}{d_{\text {anatase }}}\left(\frac{\sigma_{\text {rutil }}}{\sigma_{\text {anatase }}}\left(\frac{V_{\text {rutil }}^{m}}{V_{\text {anatse }}^{m}}\right)^{2 / 3}-1\right)
\end{aligned}
$$

Expression (6) does not take into account the effects of particle compression due to surface forces. This approximation can be used for larger particles [38], for example, having sizes of a few tens of nanometers or more. For small particles, taking into account the surface compression will lead to the transformation of expression (5) to the following:

$$
\begin{aligned}
& \Delta G_{\text {anatase } \rightarrow \text { rutil }}^{m}\left(T, P, d_{\text {anatase }}\right)=\Delta G_{b . p .(\text { anatase } \rightarrow \text { rutil })}^{m}(T, P)+ \\
& (6+4 t) \frac{\sigma_{\text {anatase }} \cdot V_{\text {anatase }}^{m}}{d_{\text {anatase }}}\left(\frac{\sigma_{\text {rutil }}}{\sigma_{\text {anatase }}}\left(\frac{V_{\text {rutil }}^{m}}{V_{\text {anatse }}^{m}}\right)^{2 / 3}-1\right),
\end{aligned}
$$


TABLE 3. Enthalpy of polymorphic transitions of $\mathrm{TiO}_{2}$

\begin{tabular}{|c|c|c|}
\hline$\Delta \mathrm{H}, \mathrm{kJ} / \mathrm{mol}$ & $\mathbf{T}, \mathbf{K}$ & References \\
\hline \multicolumn{3}{|c|}{ Anatase $\rightarrow$ Rutile } \\
\hline-3.761 & 298.15 & \multirow{2}{*}{ IVTANTHERMO [18] } \\
\hline-3.743 & 948.15 & \\
\hline-6.14 & 298.15 & JANAF [40] \\
\hline$-2.61 \pm 0.41^{1)}$ & 298 & [41] \\
\hline$-0.42 \pm 0.21$ & 903 & [42] \\
\hline$-2.93 \pm 1.26$ & 1360 & \multirow{2}{*}{ [43] } \\
\hline$-3.26 \pm 0.84$ & 971 & \\
\hline$-6.57 \pm 0.79$ & 968 & [44] \\
\hline$-8.37 \pm 5.92$ & 298 & [45] \\
\hline $0.42^{2)}$ & 298 & [46] \\
\hline $11.67^{2)}$ & 1183 & [10] \\
\hline \multicolumn{3}{|c|}{ Brucite $\rightarrow$ Rutile } \\
\hline$-0.71 \pm 0.38$ & 971 & [43] \\
\hline$-0.42 \pm 0.31$ & 715 & [42] \\
\hline$-0.84 \pm 0.42$ & 930 & [43] \\
\hline $41.84 \pm 9.36^{2)}$ & & [45] \\
\hline \multicolumn{3}{|c|}{ Amorphous $\mathrm{TiO}_{2} \rightarrow$ Rutile } \\
\hline-20.4 to- $34.0^{3)}$ & 298 & Calculation according to depend of [27] \\
\hline$-24.25 \pm 0.88^{4)}$ & 298 & [41] \\
\hline \multicolumn{3}{|c|}{ Rutile $\rightarrow$ Melt } \\
\hline 68 & 2185 & IVTANTHERMO [18] \\
\hline
\end{tabular}

Note:

1) - values recommended in [41];

2) - values indicated in [41] as causing doubt;

3) $-\Delta H_{298 \text { amophization }}=0.3-0.5 \Delta H_{\text {melt }}$, [27]; $\Delta H_{\text {melt }}\left(\mathrm{TiO}_{2}\right.$ rut $)=68 \mathrm{~kJ} / \mathrm{mol} \mathrm{IVTANTHERMO} \mathrm{[18]}$

4) $-S_{\text {surf }}=34596 \mathrm{~m}^{2} / \mathrm{mol}[41]$

where $t=1+\frac{\partial \ln \sigma}{\partial \varepsilon}$ ( $\varepsilon$ - surface deformation), in accordance with [34] with reference to the data presented in [47], in this case it can be $1 \lesssim t \lesssim 2$.

The results of thermodynamic calculation of limit values $d_{\text {anatase }}$, up to which the anatase polymorph modification of $\mathrm{TiO}_{2}$ is thermodynamically stable, for various input data options $\Delta G_{\text {anatase } \rightarrow \text { rutil }}^{m}\left(T, P, d_{\text {anatase }}\right)$, $\sigma_{\text {rutil }}(T), \sigma_{\text {anatase }}(T), t$ (Table 2, 3) are presented in Fig. 6 . The analysis of the calculated results for the limit values for anatase crystallite sizes, to which this polymorph modification is thermodynamically stable, shows that depending on possible values $\Delta G_{\text {anatase } \rightarrow \text { rutil }}^{m}\left(T, P, d_{\text {anatase }}\right), \sigma_{\text {rutil }}(T), \sigma_{\text {anatase }}(T), t$, as well as on taking into account the compression of the particles due to the surface tension forces (expression (7)), limit values $d_{\text {anatase }}$ can vary widely - from $\sim 5$ to $\sim 37 \mathrm{~nm}$ (Fig. 6). It should be noted that these calculations do not take into account dependence $\sigma(d)$, which was mentioned, for example, in [37-39]. Taking this dependence into account is appropriate in cases where the particle size is several nanometers $[28,47]$. In this case, as shown by the results of calculations of $d_{\text {anatase }}$, dependence $\sigma(d)$ can be neglected.

Despite the wide range of variability for the possible limit values of $d_{\text {anatase, }}$ associated with the choice of various thermodynamic parameters (Table 4), it is possible to determine the sensitivity of $d_{\text {anatase }}$ to changes of 
these parameters and narrow the range of the most probable values of $d_{\text {anatase. }}$ First, it should be noted that insensitivity of limit values of $d_{\text {anatase }}$ o temperature dependencies of values of $\Delta G_{b . p .(\text { anatase } \rightarrow \text { rutil) }}^{m}(T)$ and $\sigma_{\text {rutil(anatase) }}(T)$, both in the calculation $\Delta G_{b . p .(\text { anatase } \rightarrow \text { rutil) }}^{m}(T)$ according to the data of IVTANTHERMO [18], and according to the data of JANAF [40] (Fig. $6 a$ and $b$ ). In addition, the use of thermodynamic data from IVTANTHERMO and JANAF databases give substantially different limit values for $d_{\text {anatase }}$ (compare Fig. $6 a$ and 6b, Fig. $6 c$ and $6 d$ ). Due to the fact that the thermodynamic data from IVTANTHERMO were checked for self-consistency [18], and due to the higher compliance $\Delta H_{\text {(anatase } \rightarrow \text { rutil) }}$ (IVTANTHERMO) with values recommended in [41] (see Table 3), in comparison with calculated according to JANAF [40], the results obtained using the IVTANTHERMO database should be considered as more reliable.

Limit values of $d_{\text {anatase }}$ are sensitive to measurement of particle compression by surface tension (Fig. $6 \mathrm{~b}$, $c, d)$. Higher influence on the accuracy limit values of $d_{\text {anatase }}$ is observed for uncertainty in the data on the values of the surface energy of the particles (Fig. $6 \mathrm{e}$ ). If we take into account the results of the analysis of the reliability of data according on $\sigma_{\text {rutil(anatase) }}$ and $\Delta G_{b . p \text {. (anatase } \rightarrow \text { rutil) }}^{m}$, the range of possible limit values of $d_{\text {anatase }}$ is narrowed to a range of $\sim 16 \mathrm{~nm} \lesssim d_{\text {anatase }} \lesssim 37 \mathrm{~nm}$.

TABLE 4. Limit values for the sizes of the anatase particles $\left(d_{\text {anatase }}\right)$ for various calculation parameters for cases in which one particle of $\mathrm{TiO}_{2}$ with the rutile structure is formed from one particle of $\mathrm{TiO}_{2}$ with the anatase structure

\begin{tabular}{|l|c|}
\hline The parameters for calculating & $d_{\text {anatse }}, \mathrm{nm}$ \\
\hline $\begin{array}{l}\text { Calculation according IVTANTHERMO excluding compression } \\
\text { surface tension forces at different temperatures }\end{array}$ & 15.7 \\
\hline $\begin{array}{l}\text { Calculation according JANAF excluding compression } \\
\text { surface tension forces at different temperatures }\end{array}$ & 9.6 \\
\hline $\begin{array}{l}\text { Calculation according IVTANTHERMO based compression } \\
\text { of the surface tension forces }\end{array}$ & \\
\hline$t=1$ & 26.25 \\
\hline$t=1.5$ & 31.55 \\
\hline$t=2$ & 36.80 \\
\hline $\begin{array}{l}\text { Calculation according JANAF based compression } \\
\text { of the surface tension forces }\end{array}$ & 14.37 \\
\hline$t=1$ & 17.24 \\
\hline$t=1.5$ & 20.1 \\
\hline$t=2$ & 26.3 \\
\hline $\begin{array}{l}\text { Calculation according IVTANTHERMO based compression forces } \\
\text { of surface tension }(t=1) \text { depending on the values of } \sigma\end{array}$ & \\
\hline $\begin{array}{l}\sigma_{\text {rutil }}=0.71 \\
\sigma_{\text {anatase }}=0.58\end{array}$ & \\
\hline $\begin{array}{l}\sigma_{\text {rutil }}=1.91 \\
\text { anatase }\end{array}=1.32$ & \\
\hline
\end{tabular}

The thermodynamic analysis of the possibility of anatase particles transforming into rutile particles, in the case of changes in the total number of particles in the system is of interest. Such mechanism is possible, for example, in the case of merger of several anatase particles into a crystallite with rutile structure, or alternatively, in the case of crushing the crystallite of anatase into several crystallites of rutile, as was observed, in particular, in [47] dedicated to the analysis of structural transformation of $t-\mathrm{ZrO}_{2} \rightarrow m-\mathrm{ZrO}_{2}$ during cooling. By designating 



$\Delta G, \mathrm{~kJ} / \mathrm{mol}$

1. 3) $] \quad{ }^{20}$ ( Calculation according to JANAF [40] (tabl. 2.2.5)

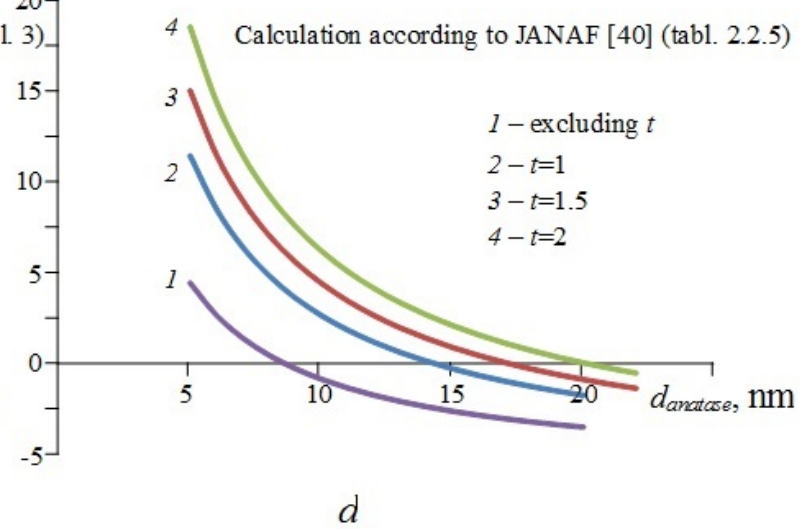

$\Delta G, \mathrm{~kJ} / \mathrm{mol}$

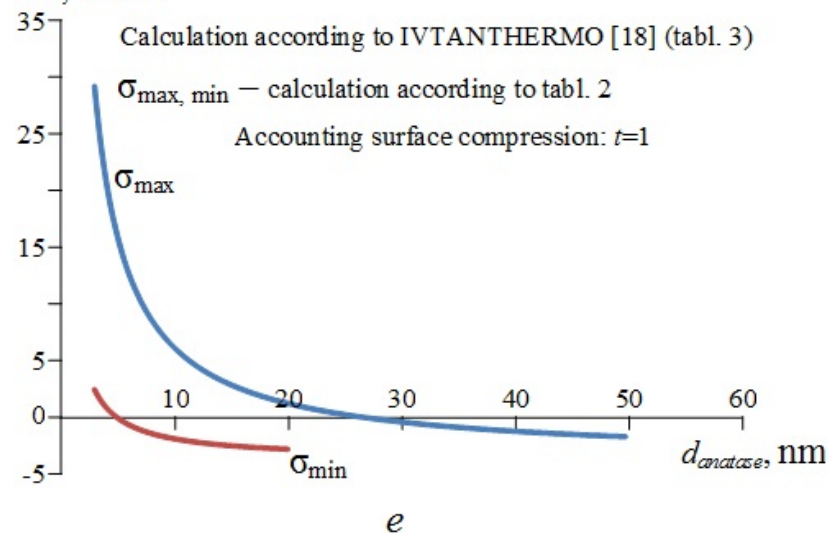

FIG. 6. Gibbs energy change in phase transition (3) depending on the anatase particle size ( $\left.d_{\text {anatase }}\right)$ for different initial data (Table 4) 
$\nu=N_{\text {anatase }} / N_{\text {rutil }}$, in the approximation of a spherical particle shape, expression (4) can be presented as:

$$
\begin{aligned}
& \Delta G_{\text {anatase } \rightarrow \text { rutil }}^{m}\left(T, P, d_{\text {anatase }}, \nu\right)=\Delta G_{b . p .(\text { anatase } \rightarrow \text { rutil })}^{m}(T, P)+ \\
& 6 \frac{\sigma_{\text {anatase }}(T) \cdot V_{\text {anatase }}^{m}}{d_{\text {anatase }}}\left(\frac{\sigma_{\text {rutil }}(T) \cdot}{\sigma_{\text {anatase }}(T)}\left(\frac{V_{\text {mutil }}^{m}}{V_{\text {anatse }}^{m}}\right)^{2 / 3} \nu^{-\frac{1}{3}}-1\right)
\end{aligned}
$$

In Fig. 7 and Table 5 the calculated results for the thermodynamic conversion possibilities of titanium dioxide with anatase structure into a rutile structure for different values of $\nu$ are presented: 1 (no changes in the number of particles in the system); 2, 3, 4 (fusion of 2, 3 and 4 particles of anatase into one rutile crystallite); 1/2, 1/3, 1/4 (anatase particle fragmentation during phase transition). The mechanism of such phase transitions for $\nu=1 / 4,1 / 3$, $1 / 2,1,2,3,4$ is presented in Fig. 8.

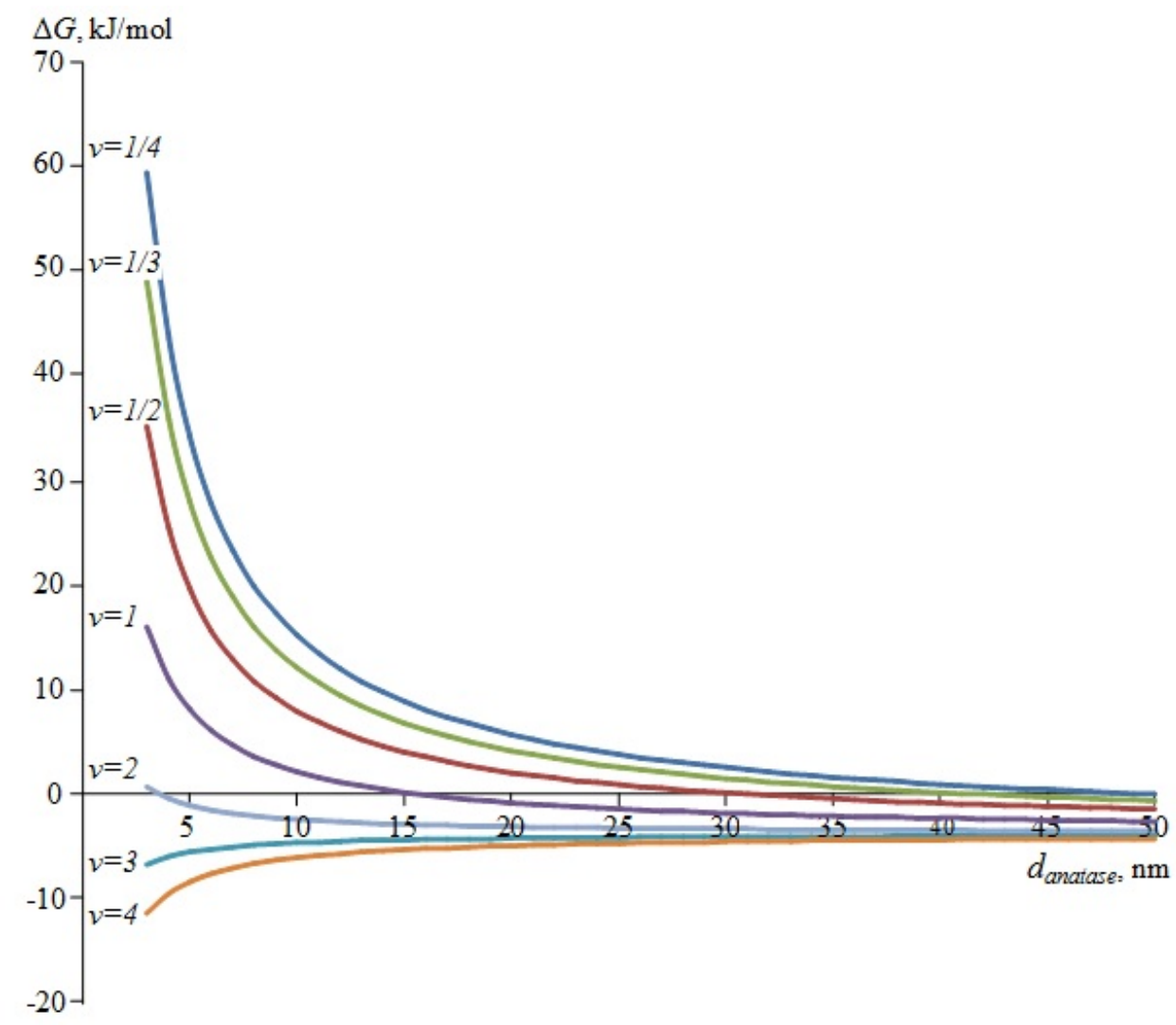

FIG. 7. Results of calculation of changes in the Gibbs energy during structural transformations (3), associated with crushing or fusion of anatase particles (for calculations, IVTANTHERMO was used, surface energy values were calculated based on expressions (1) and (2), the effect of the surface compression of the particles was not taken into account)

Calculations of dependencies $d_{\text {anatase }}(\nu)$ were carried out for Gibbs energy values for bulk phases taken from the IVTANTHERMO database, and vales $\sigma_{\text {rutil }}(T), \sigma_{\text {anatase }}(T)$ presented in the form of dependencies (1) and (2), as the most reliable, as it was shown earlier, and for the calculation option, in which the compression of particles by forces of surface tension is not considered. The results of calculations as a chart of the possible structural transformations depending on the particle size of titanium dioxide and various options crushing or fusing of particles during structural transformations are presented in Fig. 8. The results of calculations (Fig. 7, Table 5) show that if crushing of particles of anatase with the formation of several particles of rutile is possible only in the case of high values of $d_{\text {anatase }}$, which are significantly higher than the limit sizes of anatase particles, at which this modification of $\mathrm{TiO}_{2}$ is stable, the fusion of several particles of anatase with the formation of one particle of rutile, except for $\nu=2$, is possible almost at all $d_{\text {anatase }}$ values. In addition, the formed rutile particles can be unstable and undergo transition to the anatase structure (Fig. 8). In a real situation, the presence or absence of a structural transition can be influenced by the kinetic simplicity or difficulty of structural transition and growth of the particles, allowing their transition to a potentially stable, from a thermodynamic point of view, state of the rutile modification, starting with certain particle size values. 
TABLE 5. Dependence of limit values for the sizes of anatase and rutile particles in cases of crushing $(\nu<1)$ and fusion $(\nu>1)$ of anatase particles according to the data of calculations given in Fig. 7

\begin{tabular}{|c|c|c|}
\hline \multirow{2}{*}{$\nu$} & \multicolumn{2}{|c|}{ The limits of particle size (d), nm } \\
\cline { 2 - 3 } & $d_{\text {anatase }}$ & $d_{\text {rutil }}$ \\
\hline $1 / 4$ & 51 & 31 \\
\hline $1 / 3$ & 42 & 28 \\
\hline $1 / 2$ & 31 & 24 \\
\hline 1 & 16 & 16 \\
\hline 2 & 3.6 & 4.0 \\
\hline 3 & \multicolumn{2}{|c|}{ for any values } \\
\hline 4 & \multicolumn{2}{|c|}{ for any values } \\
\hline
\end{tabular}

Thus, according to the thermodynamic calculation carried out, during dehydration of $\mathrm{Ti}(\mathrm{OH})_{4}$, there is no significant thermodynamic preference to the formation of certain structural modification of titanium dioxide. The analysis of the size of the critical anatase and rutile nucleus formed during dehydration does not give reasons for discussing the preference of forming the anatase or rutile modifications of $\mathrm{TiO}_{2}$, i.e. thermodynamically and kinetically dehydration of $\mathrm{Ti}(\mathrm{OH})_{4}$ can lead to formation of $\mathrm{TiO}_{2}$ in both anatase and rutile modifications. In this situation, the preference in the formation of certain structural modifications of $\mathrm{TiO}_{2}$ will be observed for the modification, the genetic precursor of which is the substance, which is its structural analog, as was observed, for instance, for the formation of zirconium dioxide nanocrystals [48,49], or on the surface of the substance, which is structurally similar [50]. Analysis of the dependence between the stable state of anatase and rutile modifications and the particle size shows that in the case of formation of rutile particles during dehydration of $\mathrm{Ti}(\mathrm{OH})_{4}$ with a size below the limit values (Fig. 6, 7, Table 4, 5), i.e. for one of variants of calculation - less than $\sim 15 \mathrm{~nm}$ (Fig. 8), transition $\mathrm{TiO}_{2}$ (rutile) $\rightarrow \mathrm{TiO}_{2}$ (anatase) becomes possible, in contrast, for example, to zirconium dioxide, the transition of which from the thermodynamically stable monoclinic modification $\left(m-\mathrm{ZrO}_{2}\right)$ to metastable modification $t-\mathrm{ZrO}_{2}$ is not possible for all particle sizes and for all $P-T$-conditions, up to $(P, T)$, at which $t-\mathrm{ZrO}_{2}$ becomes equilibrium bulk phase. It should be noted that, in general, structural transitions are not always expected in the case of achieving the limit values of particle sizes,

$$
\mathrm{TiO}_{2}\left(\text { rutile) } \underset{d_{\text {anatase }}>d_{\text {anatase }(\mathrm{lim})}}{\stackrel{d_{\text {rutil }}<d_{\text {rutil }(\mathrm{lim})}}{\leftrightarrows}} \mathrm{TiO}_{2}\right. \text { (anatase) }
$$

since the existence of non-equilibrium structure of nanoparticles due to kinetic reasons is possible [47-49].

Due to the possibility of influencing the phase formation by sizes and shapes of space constraints $[48,51,52]$, as well as the composition and structure of the wall material of these constraints, it is of interest to examine the formation of titanium dioxide taking into account these factors. Let's consider options of localization of titanium dioxide in "infinite cylinder" type channel and on the flat surface [48]. The two cases of solid phase contacts will be analyzed: coherent fusion of the material forming walls of spatial confinement with 1) the rutile form and 2) the anatase form of $\mathrm{TiO}_{2}$.

Calculations made for regions of thermodynamically stable $\mathrm{TiO}_{2}$ as rutile and anatase for the idealized cases of spatial constraints described above have shown that in the case of coherent fusion of the material of the spatiallyconstraining walls of "cylindrical channel" or "flat surface" types with the rutile structure, the latter will stably exist without any possibility of transformation into the anatase structure. In the cases of coherent fusion of the material of the constraining walls with the anatase structure, depending on the size of the particles of $\mathrm{TiO}_{2}$, it can exist as both anatase and rutile (Fig. 9, $a, b$ ). In addition, the stability of these structures is almost independent of temperature. It should be noted that this conclusion explains the literature data on the effect of the substrate structure and the thickness of the deposited layer on the structure of the titanium dioxide layer deposited by molecular layering [50]. 


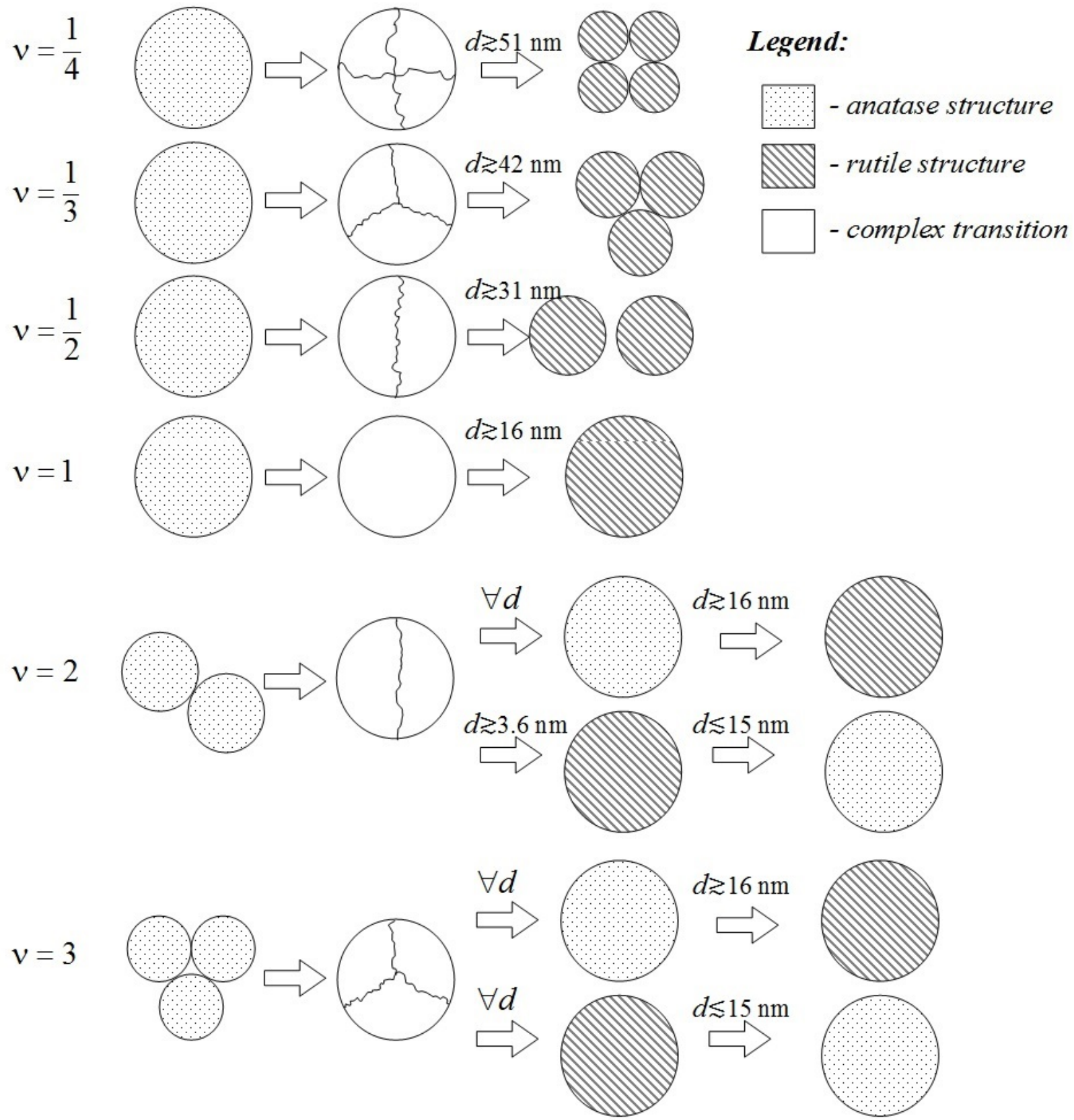

FIG. 8. Chains of possible structural transformations in titanium dioxide depending on the anatase and rutile particle size based on the results of calculation presented in Fig. 7

\section{Formation of $\mathrm{TiO}_{2}$ nanocrystals under hydrothermal synthesis and aerobic thermal treatment conditions}

As the starting material for the experimental study of methods for titanium dioxide nanocrystal formation, $\mathrm{X}$-ray amorphous hydrated titanium oxide obtained by direct precipitation with $25 \%$ ammonia solution $\mathrm{NH}_{4} \mathrm{OH}$ (extra pure grade) from diluted solution of titanium tetrachloride $\mathrm{TiCl}_{4}(0.3 \mathrm{~mol} / \mathrm{l})$ was used. Completeness of precipitation was controlled by $\mathrm{pH}$ of the solution $(\sim 10)$. The obtained precipitate was washed with distilled water in order to remove excess ammonia and chloride ions by decantation and filtration. According to elemental analysis, the obtained precipitate did not contain any traces of chloride ions or other impurities.

The hydrothermal treatment was carried out at 200 and $250{ }^{\circ} \mathrm{C}, 70 \mathrm{MPa}$, and isothermal time ranged from 10 to 240 minutes. 


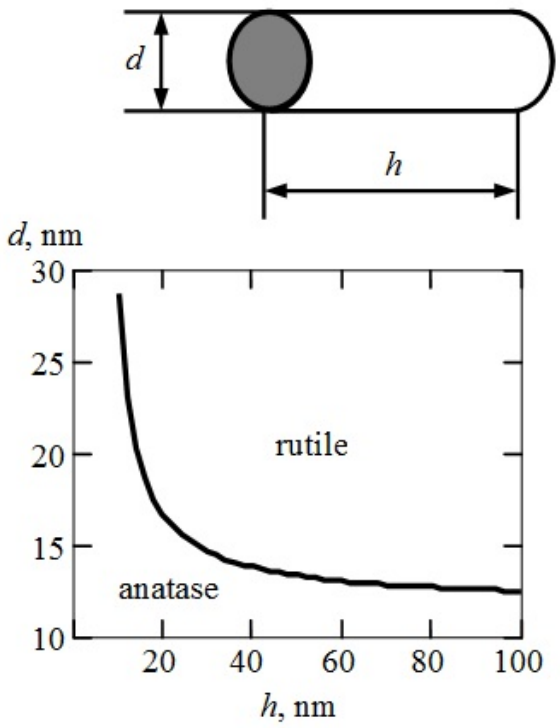

$a$


$b$

FIG. 9. Dependence of the steady state of structural modifications of $\mathrm{TiO}_{2}$ on the nanoparticles' linear dimensions in varying types of spatially-constrained conditions: a) in "infinite cylinder" type channel b) and on the flat surface, with the assumption that the material of the spatiallyconstraining walls is coherently fused with the anatase structure

The results of X-ray analysis are given in Fig. 10. According to X-ray diffraction data (Fig. 10), throughout the whole range of the hydrothermal treatment parameters, the formation of anatase crystalline titanium oxide is observed. Additionally, the size of crystallites formed is of not more than $16 \mathrm{~nm}$ (Fig. 11), which is consistent with the data obtained by thermodynamic analysis on the possibility of sustainable existence for the metastable anatase modification.

Analysis of X-ray diffraction data (Fig. 11) suggests that hydrothermal treatment of X-ray amorphous hydrated titanium oxide $\left(\mathrm{TiO}_{2} \cdot n \mathrm{H}_{2} \mathrm{O}\right)$ at $200{ }^{\circ} \mathrm{C}$ for 10 min leads to crystallization of about $0.2(20 \%)$ of titanium dioxide in the anatase form. Whereas, at $250{ }^{\circ} \mathrm{C}$, for the same time, the conversion reaches 0.85 (Fig. 10b, Fig. 10). It should be noted that the change in the crystallite size change is symbatical to the change in the conversion (Fig. 11), i.e. at $200{ }^{\circ} \mathrm{C}$ a significant increase of the size of the $\mathrm{TiO}_{2}$ crystallites occurs during a period of rapid increase in the conversion (Fig. 11), and when the conversion reaches about 0.8 , the growth rate of the crystal phase and the size of the $\mathrm{TiO}_{2}$ crystallites with the anatase structure significantly decrease.

A comparison of the curve of changes in the conversion and the curve corresponding to changes in the relative values of the average volume of crystallites $(\nu)$ (Fig. 12) suggests that at a temperature of $200{ }^{\circ} \mathrm{C}$ the formation of $\mathrm{TiO}_{2}$ nanocrystals in the anatase form from amorphous hydrated titanium oxide in the initial stage of hydrothermal treatment is mainly associated with the formation of new crystallites of anatase from the amorphous phase. In the case of increasing the isothermal time, the amount of amorphous phase decreases, which leads to a change in the predominant mechanism of crystallite growth. Upon reaching a conversion of 0.8 , an increase in the $\mathrm{TiO}_{2}$ crystallite size is mainly due to an increase in their volume during the recrystallization process. A change in the prevailing process greatly reduces the growth rate of $\mathrm{TiO}_{2}$ crystallites (Fig. 11). At a temperature of hydrothermal treatment of $250^{\circ} \mathrm{C}$, the process for forming titanium oxide nanocrystals takes place so rapidly that after 10 minutes of isothermal time the conversion is higher than 0.80 (Fig. 11), and therefore, a further increase in the size of the crystallites takes place apparently due to the recrystallization process.

It should be noted that in the case of hydrothermal treatment of amorphous hydrated $\mathrm{TiO}_{2}$ and at a temperature of $200{ }^{\circ} \mathrm{C}$ and $250{ }^{\circ} \mathrm{C}$, when the conversion is about 0.85 , the size of crystallites is about $11 \mathrm{~nm}$ (Fig. 11). Also, the speed of their growth and increase in size during further isothermal treatment are very low. The low crystallite growth rate, and therefore a small change in their sizes appears to be related to the fact that in conditions of 

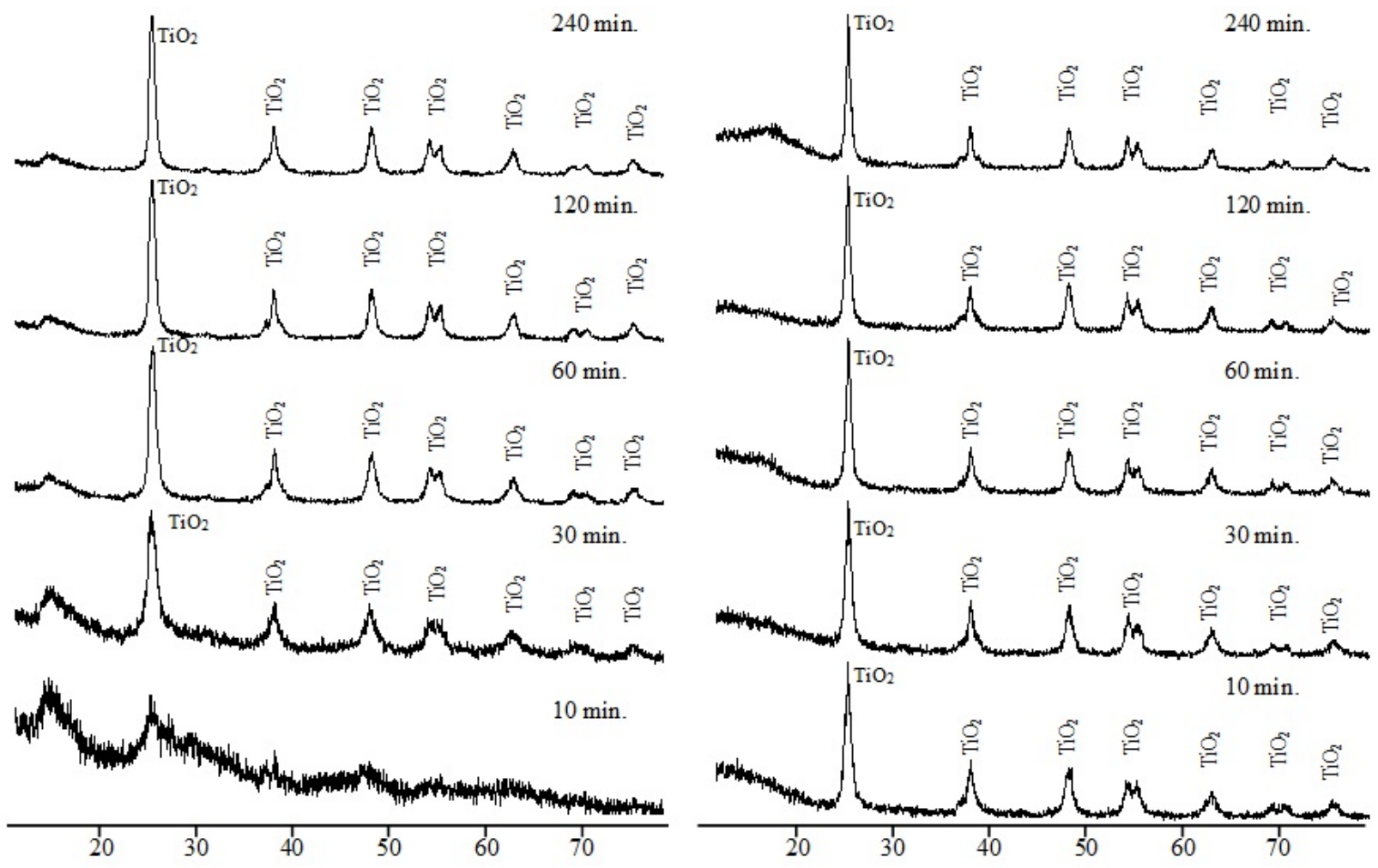

FIG. 10. X-ray diffraction patterns for samples obtained by hydrothermal treatment of hydrated titanium oxide at $T=200{ }^{\circ} \mathrm{C}()$ and $T=250{ }^{\circ} \mathrm{C}($ b) and $P=70 \mathrm{MPa}$
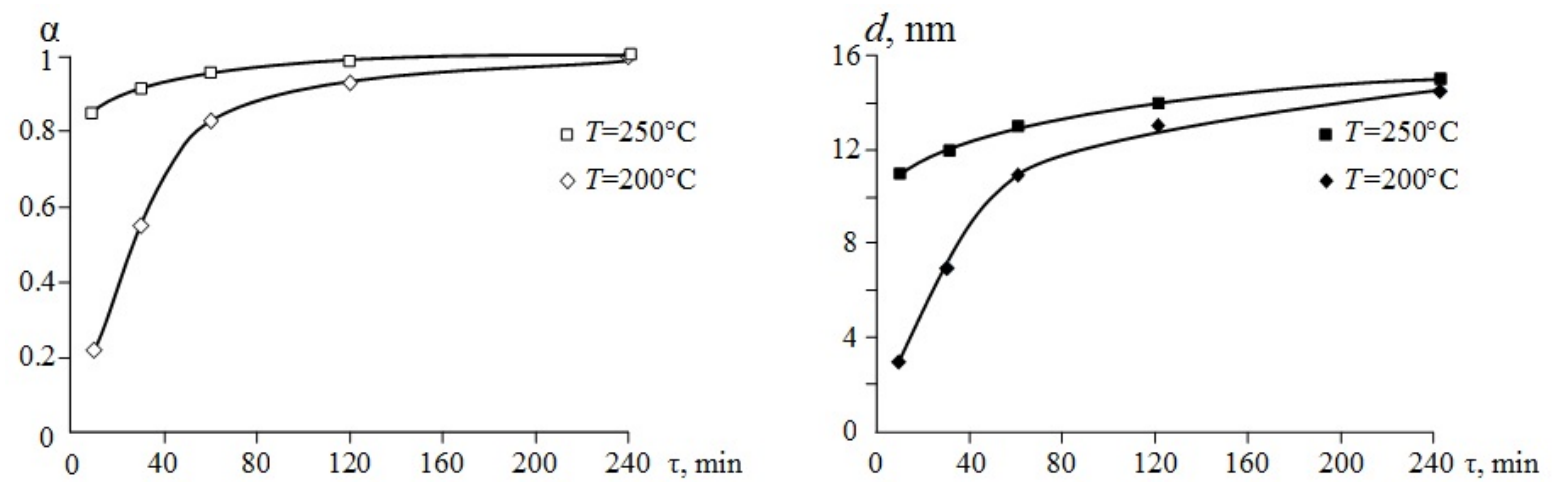

FIG. 11. Dependence of the conversion $(\alpha)$ and crystallite size (d) on the duration of the hydrothermal treatment of hydrated titanium oxide at $=200{ }^{\circ} \mathrm{C}$ and $=250{ }^{\circ} \mathrm{C}, P=70 \mathrm{MPa}$

practically avalanche-like crystallization of $\mathrm{TiO}_{2}$ nanoparticles, they are characterized by relatively narrow particle size distribution, similarly to formation of $\mathrm{ZrO}_{2}$ nanoparticles [50,51].

For the samples obtained at hydrothermal treatment temperature of $250{ }^{\circ} \mathrm{C}$, a change in the specific surface of samples has been analyzed depending on the isothermal treatment time (Fig. 13). According to the data shown in (Fig. 13), specific surface area of $\mathrm{TiO}_{2}$ nanoparticles obtained during hydrothermal treatment significantly decreases when the isothermal treatment time was changed from 30 minutes to 60 minutes. A further increase in the duration of treatment leads to a monotonic, but not significant decrease in the specific surface area of $\mathrm{TiO}_{2}$ nanoparticles.

Based on the data for the specific surface area of the titanium dioxide nanoparticles (Fig. 13), their size has been calculated assuming that the shape of particles is close to spherical. In the case of comparison of the crystallite sizes and sizes of anatase titanium dioxide particles, it can be observed that the crystallite sizes obtained based on the X-ray diffraction data are systematically lower than those of the $\mathrm{TiO}_{2}$ particles obtained based on the data on the specific surface (Fig. 14). 




a



$b$

FIG. 12. Dependence of changes of the relative values of the average crystallite volume $(\nu)$ and the degree of conversion $(\alpha)$, on the duration of the hydrothermal treatment at $T=200{ }^{\circ} \mathrm{C}$ (a) and $T=250{ }^{\circ} \mathrm{C}(\mathrm{b}), P=70 \mathrm{MPa}$

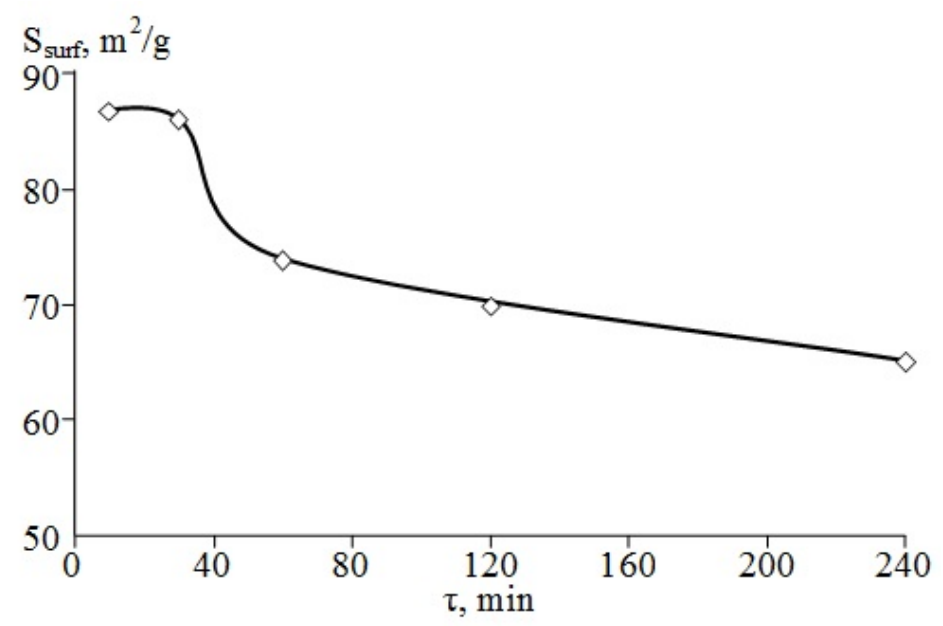

FIG. 13. Dependence of of the specific surface $\left(S_{s p}\right)$ on the duration of the hydrothermal treatment of hydrated titanium oxide at $T=250^{\circ} \mathrm{C}, P=70 \mathrm{MPa}$

This can be be due, for example, to the fact that the obtained particles contain a crystalline core, the size of which is determined based on broadening of X-ray diffraction lines and X-ray amorphous coating, the presence of which is taken into account during specific surface area determination. Such explanation of the difference in sizes of particles and crystallites is possible in cases when the proportion of the amorphous states in the system is large, i.e. at low temperatures and times of phase formation. When the temperature and time of hydrothermal treatment are $T=250{ }^{\circ} \mathrm{C}, \tau \geq 60 \mathrm{~min}$ as follows from the analysis of the data presented in Fig. 12, the proportion of the amorphous phase in the system is low. In this case, the difference between sizes of particles and crystallites is likely determined by the fact that the anatase $\mathrm{TiO}_{2}$ crystallites formed dense polycrystalline aggregates composed of 3-4 crystallites, as can be concluded based on the analysis of the $d_{\text {part }}^{3} / d_{\text {cryst }}^{3}$ ratio.

The results of complex differential thermal analysis of the $\mathrm{TiO}_{2}$ nanoparticles obtained during hydrothermal treatment of the hydrated titanium oxide are given in Fig. 15. On the DSC curve, a set of thermal effects accompanied by a change in the mass of the sample is determined (Fig. 15, Table 6).

The analysis of data presented in Fig. 16 shows that the observed exothermic heat effects in the range of $200-510{ }^{\circ} \mathrm{C}$ are not accompanied by a marked change in the structural state of $\mathrm{TiO}_{2}$ nanoparticles. Up to $600{ }^{\circ} \mathrm{C}$, in the X-ray diffraction patterns, peaks corresponding to titanium oxide in the anatase structural modification are observed. Only after heat treatment to temperatures in the area of $1000{ }^{\circ} \mathrm{C}$, the anatase $\rightarrow$ rutile transition is observed. According to this data, the structural state of titanium dioxide is shown in Table 6 . The dependence of the size of crystallites on the treatment temperature is shown in Fig. 16. 


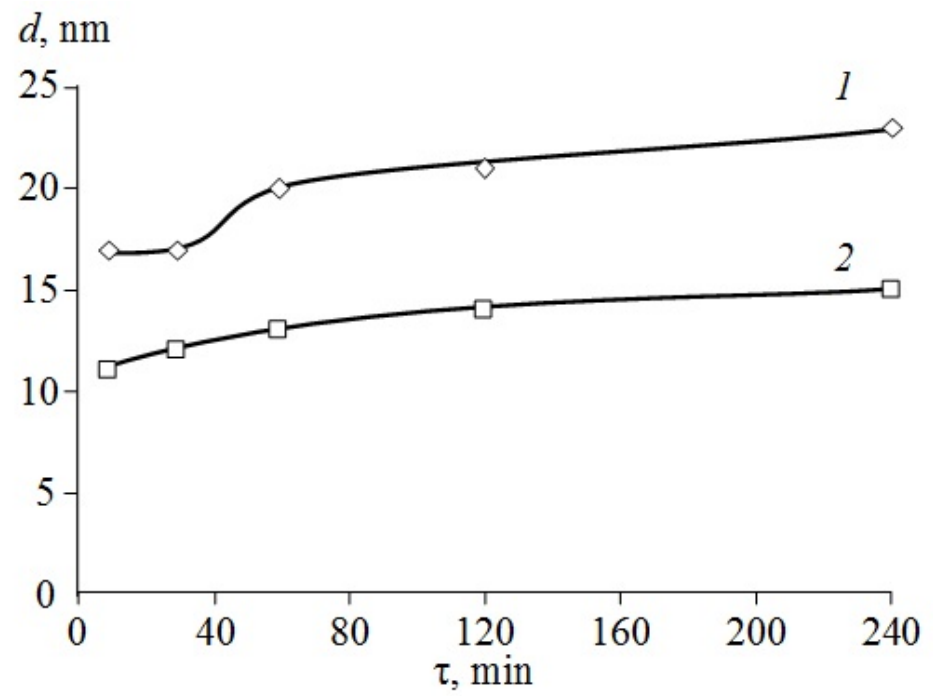

FIG. 14. Dependence of the size of $\mathrm{TiO}_{2}$ nanoparticles calculated based on the data on the specific surface area (1) and the size of crystallites of $\mathrm{TiO}_{2}$ (anatase) calculated based on X-ray diffraction data (2) on the duration of the hydrothermal treatment of hydrated titanium oxide at $T=250{ }^{\circ} \mathrm{C}, P=70 \mathrm{MPa}$

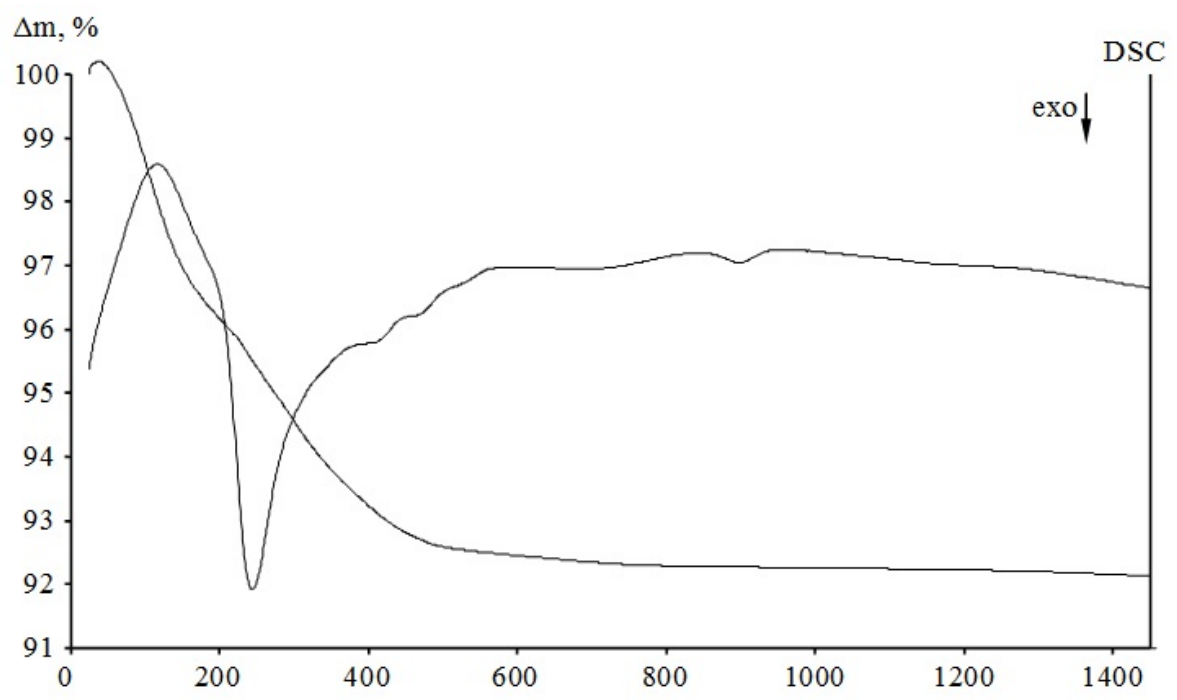

FIG. 15. Results of complex thermal analysis of $\mathrm{TiO}_{2}$ nanoparticles obtained during hydrothermal treatment of amorphous hydrated titanium oxide at $T=200{ }^{\circ} \mathrm{C}, P=70 \mathrm{MPa}$, and $120 \mathrm{~min}$ isothermal treatmen

TABLE 6. Thermal effects and changes in the weight of the sample obtained by hydrothermal treatment of amorphous hydrated titanium dioxide at $T=200{ }^{\circ} \mathrm{C}, P=70 \mathrm{MPa}$, and $120 \mathrm{~min}$ isothermal treatment

\begin{tabular}{|c|c|c|c|}
\hline Temperature range, ${ }^{\circ} \mathrm{C}$ & Nature of the thermal effect & Weight loss, $\%$ & Phase composition \\
\hline $25-200$ & endo & 4 & anatase \\
\hline $200-510$ & exo & 3.7 & anatase \\
\hline $850-950$ & exo & 0.1 & rutile \\
\hline
\end{tabular}




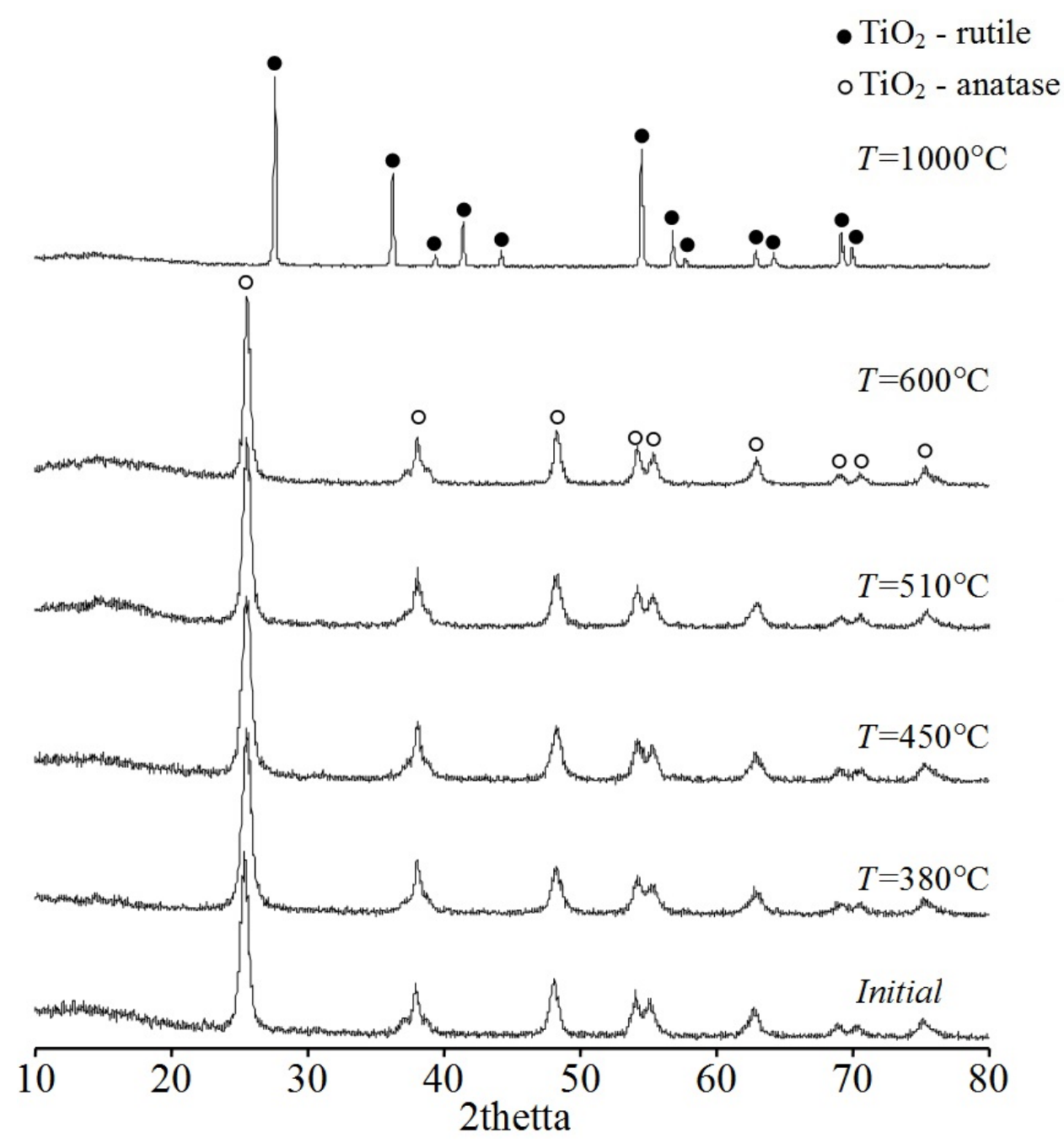

FIG. 16. X-ray diffraction patterns of the samples obtained during heating of titanium dioxide nanoparticles in air under conditions similar to used in the DSC heating mode

Thus, it seems that in the temperature range of $200-510{ }^{\circ} \mathrm{C}$ two processes occur: dehydration of remaining amorphous hydrated titanium oxide and its crystallization in the form of the anatase modification that leads to corresponding thermal effects on the thermogram (Fig. 15, Table 6). Based on the data on the weight loss in the temperature range of $200-510^{\circ} \mathrm{C}$, it can be assumed that amorphous hydrated titanium oxide component remaining after dehydration at $25-200{ }^{\circ} \mathrm{C}$ has the following formula: $\mathrm{TiO}_{2} \cdot 0.18 \mathrm{H}_{2} \mathrm{O}$.

In the high-temperature region, the exothermic effect is accompanied by a negligible change in the weight of the sample and is associated with the $\mathrm{TiO}_{2}$-anatase $\rightarrow \mathrm{TiO}_{2}$-rutile phase transformation. It should be noted that the size of the crystallites of titanium dioxide sharply increases during the transition from anatase to rutile modification and is about $50 \mathrm{~nm}$.

\section{Conclusion}

Thermodynamic analysis of processes in the $\mathrm{TiO}_{2}-\mathrm{H}_{2} \mathrm{O}$ system over a wide range of varying conditions (temperature, pressure, oxygen potential and crystalline particle size), as well as the presence of various types of space constraints allowed us to determine the regions of sustainable existence for titanium dioxide in the form of rutile and anatase modification. The results of thermodynamic prediction on the possibility and conditions for the sustainable existence of $\mathrm{TiO}_{2}$ with the rutile structure have been experimentally confirmed. The conditions and mechanisms for the formation of rutile and anatase nanocrystals during thermal treatment of amorphous hydrated titanium oxide in air and hydrothermal environments have been determined. It has been shown that the transition 
of titanium dioxide from the anatase to the rutile phase occurs by fusion and recrystallization of agglomerate consisting of three or four anatase particles with an average size of $50 \mathrm{~nm}$.

\section{Acknowledgements}

The author would like to thank Prof. V. V. Gusarov for interest in the work and help in the interpretation of results. This work was supported by the Russian Foundation for Basic Research (project No 16-03-00532).

\section{References}

[1] Chemseddine A., Moritz T. Nanostructuring titania: control over nanocrystal structure, size, shape, and organization. Eur. J. Inorg. Chem., 1999, 2, P. 235-245.

[2] Denisova T.A. Status of proton groups sorbents based oxyhydrated, geteropolimetallatnyh and tsianoferratnyh phases. Thesis for the degree of Doctor of Science. Institute of solid state chemistry of the Ural Branch of the Russian Academy of Sciences. Ekaterinburg, 2009. (in Russian)

[3] Pletnev R.N., Ivakin A.A., Kleshchev D.G., Denisova T.A., Burmistrov V.A. Hydrated oxides of group IV and V.M. Nauka, 1986 , 186 p. (in Russian).

[4] Osborn E.F. System $\mathrm{H}_{2} \mathrm{O}-\mathrm{TiO}_{2}$ : conversion of anatase to rutile in the presence of water. J. Am. Ceram. Soc., 1953, 36(5), P. 147-151.

[5] Dachille F., Roy R. A new high pressure form of titanium dioxide. Am. Ceram. Soc. Bull, 1962, 41, P. 225.

[6] Simons P.Y., Dachille F. The structure of $\mathrm{TiO}_{2} \mathrm{II}$, a high pressure phase of $\mathrm{TiO}_{2}$. Acta Crystallogr., 1967, 23 (Pt. 2 ), P. $334-335$.

[7] Bendeliany N.A., Popova S.V., Vereschagin L.F. A new modification of titanium dioxide stable at high pressure. Geochem. Int., 1966, 5, P. 387-391.

[8] McQueen R.G., Jamieson J.C. Marsh S.P. Shock wave compression and X-ray studies of titanium dioxide. Science, 1967, 155(3768), P. 1401-1404.

[9] Carli P.S, Linde R.K. Residual effects of shock waves in rutile. Meteorit. Soc., 30-th Ann Meet., Mofett Field, Calif, October, 1967.

[10] Vahldiek F.W. Phase transitions of titanium dioxide under various pressures. J. Less Common Metals, 1966, 11, P. 99-110.

[11] White W.B., Dachille F. Roy R High pressure high temperature polymorphism of the oxides of lead. J. Am. Ceram. Soc., 1961, 44, P. $170-175$.

[12] Azzaria L., Dachille F. High pressure polymorphism of manganous fluoride. J. Phys. Chem., 1961, 65, P. 889-890.

[13] Dachille F., Simons P.Y, Roy R. Pressure-temperature studies of anatase, brookite, rutile and TiO 2 -II. Am. Mineralogist, 1968, 53, P. 1929-1938.

[14] El-Akkad T.M. Effect of thermal dehydration on surface characteristics of titania gel. Thermochim. cta., 1980, 37(3), P. $269-277$.

[15] Hakonov A.I., Kontorovich S.I., Shchukin E.D. Thermal aging study "titanic acid" in the mother liquor. Izvestiya Academy Nauk USSR. Neorganicheskie materialy, 1974, 10(11), P. 2095-2096 (in Russian).

[16] Kolen'ko Yu.V., Burukhin A.A., Churagulov B.R., Oleynikov N.N. Synthesis of nanocrystalline $\mathrm{TiO}_{2}$ powders from aqueous TiOSO $_{4}$ solutions under hydrothermal conditions. Mater. Lett., 2003, 57, P. 1124-1129.

[17] Zhang S., Peng L.M., Chen Q., Du G.H., Dawson G., Zhou W.Z. Formation mechanism of $\mathrm{H}_{2} \mathrm{Ti}_{3} \mathrm{O}_{7}$ nanotubes. Phys. Rev. Lett., 2003, 91(25), P. 256103.

[18] Iorish V.S., Belov G.V. IVTANTHERMO/WIN - database and software for high temperature chemical processes modeling. 9-th Int. Conf. on High Temperature Materials Chemistry: Proceedings.- Pennsylvania (USA), 1997, P. 42.

[19] Gusarov V.V. Fast Solid-Phase Chemical Reactions. Russ. J. Gen. Chem., 1997, 67(12), P. $1846-1851$.

[20] Gusarov V.V. The thermal effect of melting in polycrystalline systems. Thermochim. Acta, 1995, 256(2), P. 467-472.

[21] Karapetyanc M.H. Methods for calculating the comparative physicochemical properties. .: Nauka, 1965. (in Russia)

[22] Almjasheva O.V. Hydrothermal synthesis, structure and properties of crystals and nanocomposites based on the system $\mathrm{ZrO}_{2}-\mathrm{Al}_{2} \mathrm{O}_{3}-\mathrm{SiO}_{2}$. Thesis for the degree of $\mathrm{PhD}$. Saint-Peterburg, 2007. (in Russian)

[23] Thermal constants of substances. Directory of 10 issues (Vol. VII). ed. Acad. VP Glushko. M., 1974. (in Russian)

[24] Hishman M.W., Benson S.W. J. Phys. Chem., 1987, 91(5), P. 5998-6009.

[25] Kumok V.N. Direct and inverse problems of chemical thermodynamics. Novosibirsk: Nauka, 1987, P. 108-128. (in Russian)

[26] Reznitsky L.A., Filippova S.E. The enthalpies of crystallization of the amorphous zirconia and solid solutions with $\mathrm{M}_{2} \mathrm{O}_{3}(\mathrm{M}-\mathrm{Y}$, Sc, Pr, $\mathrm{Nd}, \mathrm{Eu}, \mathrm{Tb}, \mathrm{Yb})$. Izvestiya Academy Nauk USSR. Neorganicheskie materialy, 1991, 27(9), P. 1841-1844. (in Russian)

[27] Reznitsky L.A. Chemical bonding and converting oxides. M.: MSU, 1978, 168 p. (in Russian)

[28] Almjasheva O.V., Gusarov V.V. Metastable clusters and aggregative nucleation mechanism. Nanosystems: Physics, Chemistry, Mathematics. 2014, 5(3), P. 405-417.

[29] Moinov S.G., Reznichenko V.A. Problemy mettalurgii titania, 1967, Moscow, USSR.

[30] Brace W.F., Walsh J.B. Some direct measurements of the surface energy of quartz and orthoclase. Am. Mineralogist, 1962, 47, P. 11111122.

[31] Terwilliger C.D., Chiang, Y. Measurements of excess enthalpy in ultrafine-grained titanium dioxide. J. Am. Ceram. Soc., 1995, 78, P. 2045-2055.

[32] Gribb A.A., Banfield J.F. Particle size effects on transformation kinetics and phase stability in nanocrystalline TiO ${ }_{2}$. Am. Mineralogist, 1997. 82, P. 717-728.

[33] Barnard A.S., Zapol P., Curtiss L.A. Modeling the morphology and phase stability of TiO 2 nanocrystals in water. J. Chem. Theory Comput., 2005, 1, P. 107-116.

[34] Zhang H., Banfield J.F. Thermodynamic analysis of phase stability of nanocrystalline titania. J. Mater. Chem., 1998, 8(9), P. 2073-2076.

[35] Barnard A.S., Zapol P. Curtiss L.A. Modeling the morphology and phase stability of $\mathrm{TiO}_{2}$ nanocrystal in water. J. Chem. Theory Comput., 2005, 1, P. 107-116.

[36] Hoang V.V. The glass transition and thermodynamics of liquid and amorphous $\mathrm{TiO}_{2}$ nanoparticles. Nanotechnology, 2008, 19(10), P. 105706. 
[37] Tolman R.C. The effect of droplet size on surface tension. J. Chem. Phys., 1949, 17(3), P. 333.

[38] Phasengleichgewichte und grenzflächenerscheinungen by A.I. Rusanov, German edition by W. Schirmer, Akademie-Verlag, Berlin, 1978, $465 \mathrm{p}$.

[39] Samsonov V.M., Bazulev A.N., Sdobnyakov N.Yu. Rusanov's linear formula for the surface tension of small objects. Dokl. Phys. Chem., 2003, 389(1-3), P. 83-85.

[40] NIST-JANAF Thermochemical Tables. http://kinetics.nist.gov/janaf/.

[41] Ranade M.R., Navrotsky A., Zhang H.Z., Banfild J.F., Elder S.H., Zaban A. Borse P.H., Kulkarni S.K., Doran G.S., Witfield H.J. Energetic of nanocrystalline $\mathrm{TiO}_{2}$. PNAS, 2002, 99(2), P. 6476-6481.

[42] Rao C.N.R. Kinetics and thermodynamics of the crystal structure transformation of spectroscopically pure anatase to rutile. Can. J. Chem., 1961, 39, P. 498-500.

[43] Mitsuhashi T., Kleppa O.J. Transformation enthalpies of the $\mathrm{TiO}_{2}$ polymorphs. J. Am. Ceram. Soc., 1979, 62(7-8), P. $356-357$.

[44] Navrotsky A., Kleppa O.J. Enthalpy of the anatase - rutile transformation. J. Am. Ceram. Soc., 1967, 50(11), 626 p.

[45] Margrave J.L., Kybett B.D. Tech.Rep. No AFMO-TR-65, 1965, 123 p.

[46] Robie R.A., Waldum D.R. Thermodynamic properties of mineral and related substances at $298.15^{\circ} \mathrm{K}\left(25.0^{\circ} \mathrm{C}\right)$ and one atmosphere $(1.013$ bars) pressure and at higher temperature. U.S. Geol. Surv. Bull., 1968, 1259, 256 p.

[47] Cammarata R.C., Sieradzki K. Surface and Interface Stresses. Annu. Rev. Mater. Sci., 1994, 24, P. $215-234$.

[48] Gusarov V.V., Almjasheva O.V. The role of non-autonomous state of matter in the formation of structure and properties of nanomaterials. Chapter 13 in the book Nanomaterials: properties and promising applications. Ed A.B. Yaroslavtsev. Scientific World Publishing House, Moscow, 2014, P. 378-403. (in Russian)

[49] Vasilevskay A.K., Almjasheva O.V., Gusarov V.V. Peculiarities of structural transformations in zirconia nanocrystals. Journal of Nanoparticle Research, 2016, 18(7), P. 188.

[50] Pozhidaeva O.V., Korytkova E.N., Romanov D.P., Gusarov V.V. Formation of $\mathrm{ZrO}_{2}$ nanocrystals in hydrothermal media of various chemical compositions. Russ. J. Gen. Chem., 2002, 72(6), P. 849-853.

[51] Sharikov F.Yu., Almjasheva O.V., Gusarov V.V. Thermal analysis of formation of $\mathrm{ZrO}_{2}$ nanoparticles under hydrothermal conditions. Russ. J. Inorg. Chem., 51(10), P. 1538-1542.

[52] Gusarov V.V., Malkov A.A., Malygin A.A. Suvorov S.A. Aluminum titanate formation in compositions with a high level of spatial and structural coupling components. Russ. J. Gen. Chem., 1994, 64(4), P. 554.

[53] Al'myasheva O.V., Gusarov V.V. Nucleation in media in which nanoparticles of another phase are distributed. Dokl. Phys. Chem., 2009, 424(2), P. 43-45.

[54] Al'myasheva O.V., Gusarov V.V. Features of the phase formation in the nanocomposites. Russ. J. Gen. Chem., 2010, 80(3), P. 385-390. 